\title{
Correction: Report of the inaugural Interferon Research Summit: interferon in inflammatory diseases
}

Crow MK, Ronnblom L. Report of the inaugural Interferon Research Summit: interferon in inflammatory diseases. Lupus Science $\mathcal{E}$ Medicine 2018;5:e00276. doi: 10.1136/lupus-2018-000276

The authors want to alert readers to the following two errors identified in the published version.

At page 4 (column 1, 2nd sentence of last paragraph), the sentence should read as: "Young women (35-44 years) with SLE have a 50-fold increased risk of vascular complications..."

In Table 1, the row under the drug "Anifrolumab" states that the drug is at Phase II for Sjögren's syndrome. This has been stated incorrectly and has been removed. The updated Table 1 is now available below:

Table 1 Therapeutic agents targeting components of the type I IFN pathway and in clinical development for IFN-driven diseases

\begin{tabular}{|c|c|c|c|}
\hline Drug & Drug MOA & Development status & Disease \\
\hline RSLV132 & RNA hydrolysis & Phase II & $\begin{array}{l}\text { Systemic lupus } \\
\text { erythematosus } \\
\text { Sjögren's syndrome }\end{array}$ \\
\hline SM101 & $\begin{array}{l}\text { Anti-immune } \\
\text { complex }\end{array}$ & Phase II & $\begin{array}{l}\text { Systemic lupus } \\
\text { erythematosus } \\
\text { Lupus nephritis }\end{array}$ \\
\hline BIIB059 & Anti-BDCA2 (pDCs) & Phase II & $\begin{array}{l}\text { Systemic lupus } \\
\text { erythematosus }\end{array}$ \\
\hline MEDI-7734 & Anti-ILT7 (pDCs) & Phase I & $\begin{array}{l}\text { Dermatomyositis } \\
\text { Polymyositis } \\
\text { Systemic sclerosis } \\
\text { Sjögren's syndrome } \\
\text { Systemic lupus } \\
\text { erythematosus }\end{array}$ \\
\hline JNJ-55920839 & Anti-IFN- $\alpha / \omega$ & Phase I & $\begin{array}{l}\text { Systemic lupus } \\
\text { erythematosus }\end{array}$ \\
\hline AGS-009 & Anti-IFN- $\alpha$ & Phase I* & $\begin{array}{l}\text { Systemic lupus } \\
\text { erythematosus }\end{array}$ \\
\hline \multirow[t]{2}{*}{ IFN- $\alpha$-kinoid } & Anti-IFN- $\alpha$ & Phase II & Dermatomyositis \\
\hline & & Phase II & $\begin{array}{l}\text { Systemic lupus } \\
\text { erythematosus }\end{array}$ \\
\hline \multirow[t]{2}{*}{ Anifrolumab } & Anti-IFNAR1 & Phase II & Lupus nephritis \\
\hline & & Phase III & $\begin{array}{l}\text { Systemic lupus } \\
\text { erythematosus }\end{array}$ \\
\hline Baricitinib† & JAK1/JAK2 inhibitor & Phase II & $\begin{array}{l}\text { Systemic lupus } \\
\text { erythematosus }\end{array}$ \\
\hline PF-04965842 & JAK1 inhibitor & Phase II & $\begin{array}{l}\text { Systemic lupus } \\
\text { erythematosus }\end{array}$ \\
\hline
\end{tabular}

${ }^{*}$ Development status unknown.

†European Medicines Agency approved for rheumatoid arthritis.

IFN, interferon; IFNAR1, type I interferon alpha receptor subunit 1; ILT7, immunoglobulin-like transcript 7; JAK, Janus kinase; MOA, mechanism of action; pDCs, plasmacytoid dendritic cell.

In the legend of figure 1, the term 'interferon-stimulating genes' appears. The correct term is 'interferon-stimulated genes'. 

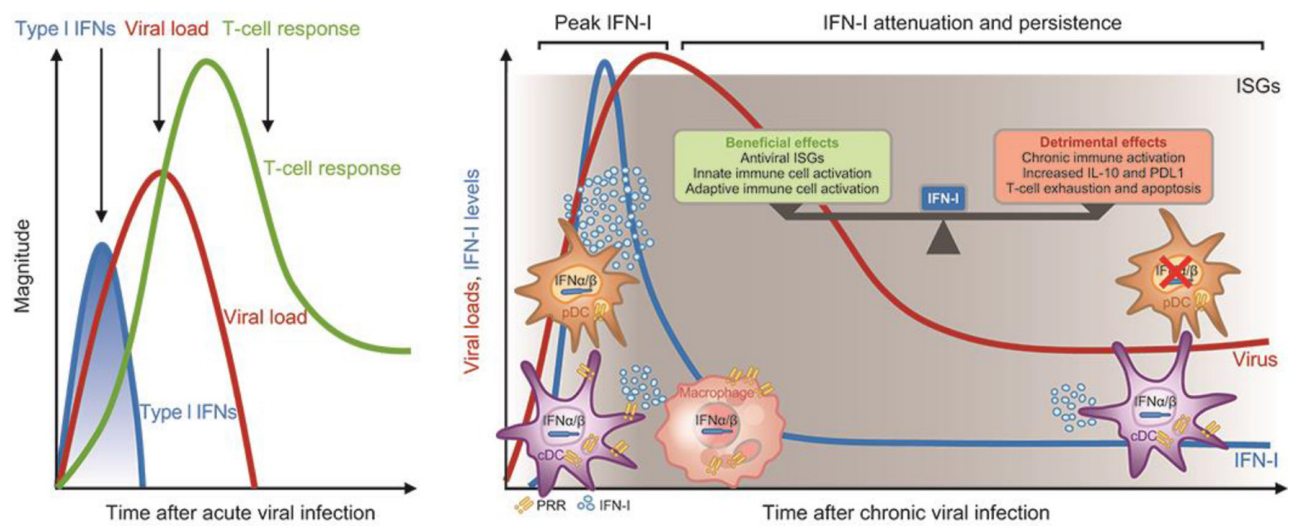

Figure 1 The role of IFN in viral infection over time. cDC, conventional dendritic cell; IFN, interferon; IL, interleukin; ISG, interferon-stimulated genes; PDC, plasmacytoid dendritic cells; PD-L1, programmed death ligand 1; PRR, pattern recognition receptor. Left panel adapted from Crouse $\mathrm{J}$ et $\mathrm{al}{ }^{9}$; right panel adapted from Zuniga El et $\mathrm{al}^{10}$ (Reprinted by permission from Springer Customer Service Centre GmbH: Springer Nature, Nature Reviews Immunology; Regulation of antiviral T cell responses by type I interferons. Crouse J, Kalinke U, Oxenius A, ( ) 2015. Republished with permission of Annual Reviews, from Innate and Adaptive Immune Regulation During Chronic Viral Infections, Zuniga El, Macal M, Lewis GM, et al, Vol. 2, (c 2015; permission conveyed through Copyright Clearance Center).

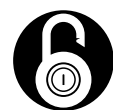

\section{OPEN ACCESS}

Open access This is an Open Access article distributed in accordance with the Creative Commons Attribution Non Commercial (CC BY-NC 4.0) license, which permits others to distribute, remix, adapt, build upon this work non-commercially, and license their derivative works on different terms, provided the original work is properly cited and the use is non-commercial. See: http://creativecommons.org/licenses/by-nc/4.0

Lupus Sci Med 2018;5:e000276corr1. doi:10.1136/lupus-2018-000276corr1

A Check for updates 